\title{
Adherence to Positive Airway Pressure therapy as Severity of Adult Obstructive Sleep Apnea
}

\author{
Seongbin Park ${ }^{\mathbb{D}}$, Min Young Seo ${ }^{\mathbb{D}}$, Min Kyu Lee ${ }^{\mathbb{D}}$, Mun Soo Han ${ }^{\mathbb{D}}$, \\ Jun Yoo iD, Sun Jin Hwang iD, and Seung Hoon Lee ${ }^{\text {iD }}$ \\ Department of Otorhinolaryngology-Head and Neck Surgery, Korea University Ansan Hospital, Korea University College of Medicine, \\ Ansan, Korea
}

성인에서 수면무호흡 중증도와 양압기 순응도와의 관련성

박성빈 · 서민영 · 이민규 · 한문수 · 유 준 · 황선진 · 이승훈

고려대학교 의과대학 안산병원 이비인후-두경부외과학교실

Received June 22, 2021

Revised August 11, 2021

Accepted September 13, 2021

Address for correspondence

Seung Hoon Lee, MD, PhD

Department of Otorhinolaryngology-

Head and Neck Surgery,

Korea University Ansan Hospital,

123 Jeokgeum-ro, Danwon-gu,

Ansan 15355, Korea

Tel $+82-31-412-5270$

Fax $+82-31-412-5174$

E-mail shleeent@korea.ac.kr
Background and Objectives The aim of this study was to compare adherence to positive airway pressure (PAP) therapy in patients with obstructive sleep apnea (OSA) of different severity. Subjects and Method We conducted a retrospective study including 270 adult OSA patients who used a PAP device for at least 3 months. We assessed the percentage of days on which the device was used, the percentage of days on which the device was used for $\geq 4 \mathrm{~h}$, and the average duration of PAP device usage at 12 weeks of PAP therapy. We also evaluated adequate adherence to PAP therapy using a PAP device for $\geq 4 \mathrm{~h} /$ day and during $\geq 70 \%$ of nights. Results The percentage of days on which a PAP device used did not differ significantly according to OSA severity (median [Q1-Q3]; mild: $91.40 \%$ [81.25\% $-97.65 \%]$, moderate: $94.50 \%$ $[86.90 \%-100 \%]$, severe: $95.90 \%[88.10 \%-100 \%], p=0.268)$. We also found that the percentage of days on which a PAP device was used during sleep for $\geq 4 \mathrm{~h}$ was not significantly different in patients with different OSA severity (median [Q1-Q3], mild: 76.20\% [69.70\%-89.90\%], moderate: $89.30 \%$ [67.65\%-95.70\%], severe: $85.70 \%$ [75.85\%-95.45\%], $p=0.097$ ). The percentage of patients with adequate PAP adherence did not differ significantly according to OSA severity (mild: $74.2 \%$, moderate: $72.1 \%$, severe: $83.0 \%, p=0.084$ ). Moreover, the mean duration (minutes) of PAP device usage during sleep did not differ significantly according to OSA severity in the mild, moderate, and severe OSA groups (mean \pm standard deviation, mild: $348.03 \pm$ $47.78 \mathrm{~min}$, moderate: $358.58 \pm 85.22 \mathrm{~min}$, severe: $363.79 \pm 57.21 \mathrm{~min}, p=0.440$ ).

Conclusion Adherence to PAP therapy did not differ significantly according to OSA severity. Therefore, it is necessary to continuously expand and maintain the insurance for health promotion in OSA patient in South Korea.

Korean J Otorhinolaryngol-Head Neck Surg 2022;65(3):150-6

Keywords Continuous positive airway pressure; Obstructive sleep apnea; Treatment adherence and compliance.

\section{Introduction}

Obstructive sleep apnea (OSA) is a respiratory disorder

This is an Open Access article distributed under the terms of the Creative Commons Attribution Non-Commercial License (https://creativecommons.org/licenses/by-nc/4.0) which permits unrestricted non-commercial use, distribution, and reproduction in any medium, provided the original work is properly cited. characterized by repetitive upper airway obstruction, which leads to nocturnal hypoxia, hypercapnia, arousal during sleep, and associated sympathetic activation during sleep. These events cause various medical comorbidities, including diabetes mellitus, hypertension (HTN), and major cardiovascular events. ${ }^{1)}$ Therefore, proper management of OSA is essential 
to prevent these complications. The treatment of OSA aims to maintain upper airway patency during sleep, and positive airway pressure (PAP) therapy is a first-line treatment modality for moderate-to-severe OSA as well as some mild OSA cases. ${ }^{2)}$ It has been reported that PAP therapy not only improves quality of life but also reduces the risk of cardiovascular complications and sudden death in patients with OSA. ${ }^{3-5)}$ Although PAP therapy is an effective treatment modality for OSA, it has significant limitations in terms of adherence. $\left.{ }^{6}\right)$ Weaver and Grunstein ${ }^{7)}$ reported that approximately 29\% to $83 \%$ of OSA patients are non-adherent to PAP therapy. Therefore, it is very important to assess the factors related to PAP adherence and take appropriate treatment accordingly.

Since July 2018, the Korean National Health Insurance Service (NHIS) has been covering PAP therapy in patients with moderate-to-severe OSA (apnea-hypopnea index $[\mathrm{AHI}] \geq 15$ ) and some complicated patients (lowest $\mathrm{SpO}_{2}<85 \%$ or lowest $\mathrm{SpO}_{2} \geq 85 \%$ with insomnia, daytime sleepiness, cognitive disorder, mood disorder, HTN, history of cardiovascular disease or history of cerebrovascular disease) in mild OSA ( $5 \leq \mathrm{AHI}$ $<15$ ). The NHIS initially covers $80 \%$ of PAP device rental fee during the 3-month PAP device adaptation period and continues to provide the patients who use the device for $\geq 4 \mathrm{~h} /$ day and on $70 \%$ of 30 consecutive days with financial benefits; they pay only approximately 15 United States dollars per month for the PAP device rental fee. However, according to a recent announcement, the NHIS is considering to reduce the benefit for patients with an AHI value of 5 to 10 are under the assumption of reduced adherence to PAP therapy in these patients. Therefore, we conducted this study to compare the adherence to PAP therapy in patients with different OSA severity. Moreover, we compare the adherence to PAP therapy in patients with mild OSA by categorizing them according to their AHI values by 10 criteria.

\section{Subjects and Methods}

\section{Participants}

We retrospectively reviewed collected data obtained from 286 adult subjects who used a PAP device for at least 3 months of OSA treatment between July 2018 and October 2020 under NHIS coverage. Among these 286 subjects, three with mild OSA, six with moderate OSA, and six with severe OSA returned the PAP device for the discomfort associated with PAP device usage. Finally, 270 patients were included in the present study (acceptance rate of PAP therapy=94.4\%) (Fig. 1). All

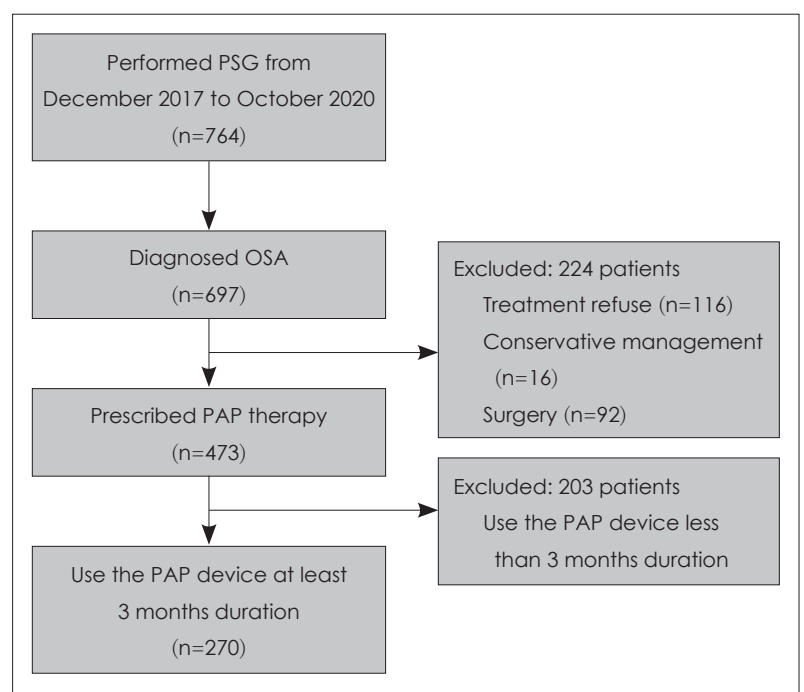

Fig. 1. Flowchart representing patient selection. PSG, polysomnography; OSA, obstructive sleep apnea; PAP, positive airway pressure.

subjects underwent sinonasal and oropharyngeal endoscopic evaluation and CT scan for upper airway assessment. For the diagnosis of OSA and the assessment of OSA severity, subjects underwent full-night technician-attended polysomnography (PSG) in our tertiary hospital. After the diagnosis of OSA, when the physician decided PAP therapy as the treatment modality for OSA, PAP titration was performed manually by well-trained sleep technicians at the sleep study center of our tertiary hospital and reviewed by certified sleep physicians. Thereafter, the physician prescribed an autoPAP device (Dream Station Auto CPAP; Philips Respironics, Murrysville, PA, USA) according to the optimal pressure range (optimal pressure $\pm 2 \mathrm{cmH}_{2} \mathrm{O}$ ). Patients visited the outpatient clinic of our hospital at 2, 5, and 12 weeks after PAP initiation to modulate the device and mask setting according to the data recorded in their devices. In this study, we assessed the adherence to PAP therapy as the percentage of days on which the device was used (number of days on which the device was used/follow-up duration), the percentage of days on which the device was used for $\geq 4 \mathrm{~h}$ (number of days on which the device was used for $\geq 4 \mathrm{~h}$ /follow-up duration), and the average duration of daily PAP device usage (total duration of PAP device usage/total number of days on which the device was used) at the third visit (12 weeks after PAP therapy). ${ }^{8)}$ We also determined the adequate adherence to PAP therapy according to the Centers for Medicare and Medical Services guidelines by using a PAP device for $\geq 4 \mathrm{~h} /$ day and during $\geq 70 \%$ of nights. ${ }^{6}$ ) This study was approved by the Institutional Ethics Committee of our tertiary hospital (2020AS0307). 


\section{Polysomnographic evaluation}

Full-night technician attended PSG was performed using an Alice 6 device (Philips Respironics) at our institute's sleep center according to the standard of the American Academy of Sleep Medicine, which recommends neurophysiologic and respiratory evaluation. ${ }^{9)}$ The polysomnographic data were manually scored by well-trained sleep technicians and reviewed by certified sleep physicians. Apnea was defined as $>90 \%$ reduction in airflow, and hypopnea was defined as $\geq 30 \%$ reduction ni airflow with a decrease in $\mathrm{SpO}_{2}$ level $\geq 4 \%$ for at least 10 seconds. We diagnosed OSA as an $\mathrm{AHI} \geq 5$ and classified OSA by severity into mild (AHI: $5-15$ ), moderate (AHI: 15-30), and severe (AHI: $\geq 30$ ) groups.

\section{Statistical analysis}

Statistical analysis was carried out using SPSS version 21.0 (IBM Corp., Armonk, NY, USA) and GraphPad Prism 7.0 (GraphPad Software, San Diego, CA, USA). To analyze the demographics of participants or PAP device usage data, categorical variables were compared using Fisher's exact test, whereas continuous variables were compared using one-way analysis of variance or Kruskal-Wallis test with Bonferroni correction according to the distribution of the data. We also performed the linear by linear analysis for determining the percentage of patients with adequate adherent patients in the mild, moderate, and severe OSA groups. Data are reported as mean \pm standard deviation and median (interquartile range, Q1-Q3).

\section{Results}

Among 270 study subjects, 244 were male. The mean age of study subjects was $49.22 \pm 10.87$ years. The mean and me- dian values of the percentage of days on which subjects used the device of were $90.03 \pm 14.21 \%$ and $94.9 \%(85.7 \%-100 \%)$, respectively. The mean and median values of the percentage of days on which subjects used the device for $\geq 4 \mathrm{~h}$ were $80.13 \pm$ $20.61 \%$ and $85.7 \%(72.4 \%-95.2 \%)$, respectively. The mean and median values of the average duration of daily PAP device usage were $360.61 \pm 64.39 \mathrm{~min}$ and $362.50 \mathrm{~min}$ (324-400 min), respectively. In this study, 31, 68, and 171 subjects were diagnosed with mild, moderate, and severe OSA, respectively. The percentage of patients who were eligible for NHIS financial benefits in the mild, moderate, and severe OSA groups were approximately $83.9 \%(26 / 31), 88.3 \%(60 / 68)$, and $97.7 \%$ (167/171), respectively. We further divided 31 mild OSA patients into two categories according to their AHI values: AHI value 5-10 and AHI value 10-15 groups; 86.7\% (13/15) patients in the AHI value 5-10 group and $81.3 \%$ (13/16) patients in the AHI value 10-15 group were eligible for NHIS financial benefits. Table 1 describes patients' overall demographic characteristics according to their OSA severity.

The percentage of days on which patients used a PAP device during sleep did not differ significantly according to OSA severity in the mild, moderate, and severe OSA groups (Table 2). There was also no difference in the percentage of days on which patients used a PAP device during sleep between the AHI value 5-10 and the AHI value 10-15 groups (AHI value 5-10 group: $94.30 \%$ [83.30\%-100\%] vs. AHI value $10-15$ group: $88.55 \%$ [77.15\%-96.63\%], $p=0.313$ ). We also found that the percentage of days on which a PAP device was used for $\geq 4$ h during sleep did not differ significantly according to OSA severity; the percentage showed a tendency to increase with an increase in OSA severity (Table 2). Moreover, in the subgroup analysis in the mild OSA group, the AHI value 1015 group showed lower percentage of days on which a PAP

Table 1. Demographic data of study subjects according to OSA severity

\begin{tabular}{|c|c|c|c|c|}
\hline & Mild OSA $(n=31)$ & Moderate OSA $(n=68)$ & Severe OSA $(n=171)$ & $p$ value \\
\hline Age (years) & $46.32 \pm 8.84(47[40-52])$ & $51.87 \pm 10.20(54[43-59])$ & $48.70 \pm 11.29(51$ [40-57]) & $0.015 * \S$ \\
\hline $\operatorname{Sex}(M: F)$ & $28: 3$ & $59: 9$ & $157: 14$ & $0.480^{\ddagger}$ \\
\hline $\mathrm{BMI}\left(\mathrm{kg} / \mathrm{m}^{2}\right)$ & $25.64 \pm 3.01(25.7[23.4-27.2])$ & $26.30 \pm 2.72(26.0[24.5-28.1])$ & $29.35 \pm 4.79(28.5[26.0-31.6])$ & $<0.001^{* \S}$ \\
\hline $\mathrm{AHI}$ (/hour) & $9.88 \pm 2.86(10.1[7.7-12.2])$ & $21.18 \pm 4.31(21.3[17.1-25.1])$ & $59.55 \pm 18.78(60.8[43.1-70.9])$ & $<0.001^{* \S}$ \\
\hline RDI (/hour) & $23.28 \pm 9.09(23.0[15.6-30.0])$ & $31.90 \pm 8.58(30.4[26.1-35.5])$ & $65.37 \pm 16.98(64.4[54.8-73.8])$ & $<0.001^{* \S}$ \\
\hline $\begin{array}{l}\text { Arousal index } \\
\text { (/hour) }\end{array}$ & $30.97 \pm 16.18(28.4[18.9-39.5])$ & $34.80 \pm 11.27(34.2[25.9-40.3])$ & $62.85 \pm 18.25(62.1[50.6-70.6])$ & $<0.001^{* \S}$ \\
\hline $\operatorname{minSaO}(\%)$ & $78.82 \pm 12.28(82[75-86])$ & $78.09 \pm 7.24(79[75-83])$ & $66.29 \pm 10.85(70[61-77])$ & $<0.001^{* \S}$ \\
\hline ODI (/hour) & $8.12 \pm 2.89(8.8[5.5-10.3])$ & $18.05 \pm 5.40(18.0[14.5-22.3])$ & $55.14 \pm 20.48(55.5[39.6-67.3])$ & $<0.001^{\dagger \S}$ \\
\hline
\end{tabular}

Data are mean \pm standard deviation (median [Q1-Q3]). Statistical significance level of $p<0.05 .{ }^{*}$ Kruskal wallis test; ${ }^{\dagger}$ one way analysis of variance with Bonferroni correction; łFisher's exact test; 'statistically significant. OSA, obstructive sleep apnea; BMI, body mass index; AHI, apnea-hypopnea index; RDI, respiratory disturbance index; ODI, oxygen desaturation index 
device was used for $\geq 4 \mathrm{~h}$ than the AHI value 5-10 group although the difference was not statistically significant (AHI value $5-10$ group: $83.90 \%$ [72.40\%-91.30\%] vs. AHI value $10-15$ group: $74.05 \%$ [64.15\%-85.25\%], $p=0.115$ ).

We determined the adequate adherence to PAP therapy in patients according to the Centers for Medicare and Medical Services guidelines by using a PAP device for $\geq 4 \mathrm{~h} /$ day and during $\geq 70 \%$ of nights. ${ }^{6}$ We found that the percentages of patients with adequate adherence to PAP did not differ significantly according to OSA severity (mild: $74.2 \%$, moderate: $72.1 \%$, severe: $83.0 \%, p=0.084$ ). In addition, the percentage of patients with adequate adherence to PAP did not show significant difference between the AHI value 5-10 and the AHI value $10-15$ groups (AHI value $5-10$ group: $86.7 \%$ vs. AHI value $10-15$ group: $62.5 \%, p=0.245$ ) (Fig. 2).

The mean duration (minutes) of PAP device usage during sleep did not differ significantly according to OSA severity (mild: $348.03 \pm 47.78 \mathrm{~min}$, moderate: $358.58 \pm 85.22 \mathrm{~min}$, severe: $363.79 \pm 57.21 \mathrm{~min}, p=0.440$ ). It also showed no difference between the AHI value 5-10 and the AHI value 10-15 groups (AHI value $5-10$ group: $361.53 \pm 33.19 \mathrm{~min}$ vs. AHI value 10-15 group: $335.38 \pm 56.44 \mathrm{~min}, p=0.405$ ) (Fig. 3).

\section{Discussion}

In the present study, there were no significant differences in various parameters regarding adherence to PAP therapy (i.e., the percentage of days on which the device was used, the percentage of days on which the device was used for $\geq 4 \mathrm{~h}$, and the average duration of daily PAP device usage) among patients with different OSA severity. To date, many studies have been conducted to elucidate the factors related to adherence to PAP therapy. ${ }^{6}$ In particular, although many studies have reported OSA severity as one of the factors that affect adherence to PAP therapy, their results differ. Riachy, et al. ${ }^{10)}$ performed a cross-sectional study with 138 OSA patients and reported that the mean respiratory disturbance index and oxygen desaturation index were significantly higher, and the minimum $\mathrm{SaO}_{2}$ value during sleep was significantly lower in the adequate adherent group at 3 months after PAP therapy than non-adherent group. In addition, Campos-Rodriguez, et al. ${ }^{11}$ performed a cross-sectional study with 357 OSA patients and

Table 2. Adherence of PAP therapy as OSA severity

\begin{tabular}{|c|c|c|c|c|}
\hline OSA severity & $\begin{array}{l}\text { Percentage of days on which patients } \\
\text { used a PAP device }\end{array}$ & p value & $\begin{array}{c}\text { Percentage of days on which a PAP } \\
\text { device was used for } \geq 4 \mathrm{~h}\end{array}$ & $p$ value \\
\hline Mild $(n=31)$ & 91.40 [81.25-97.65] & 0.268 & 76.20 [69.70-89.90] & 0.097 \\
\hline Moderate $(n=68)$ & $94.50[86.90-100]$ & & 89.30 [67.65-95.70] & \\
\hline Severe $(n=171)$ & $95.90[88.10-100]$ & & 85.70 [75.85-95.45] & \\
\hline $5 \leq \mathrm{AHI}<10(\mathrm{n}=15)$ & $94.30[83.30-100]$ & 0.313 & 83.90 [72.40-91.30] & 0.115 \\
\hline $10 \leq \mathrm{AHI}<15(\mathrm{n}=16)$ & 88.55 [77.15-96.63] & & 74.05 [64.15-85.25] & \\
\hline Moderate $(n=68)$ & $94.50[86.90-100]$ & & 89.30 [67.65-95.70] & \\
\hline Severe $(n=171)$ & $95.90[88.10-100]$ & & 85.70 [75.85-95.45] & \\
\hline
\end{tabular}

Kruskal-wallis test. Data are median [Q1-Q3]. PAP, positive airway pressure; OSA, obstructive sleep apnea; AHI, apnea-hypopnea index
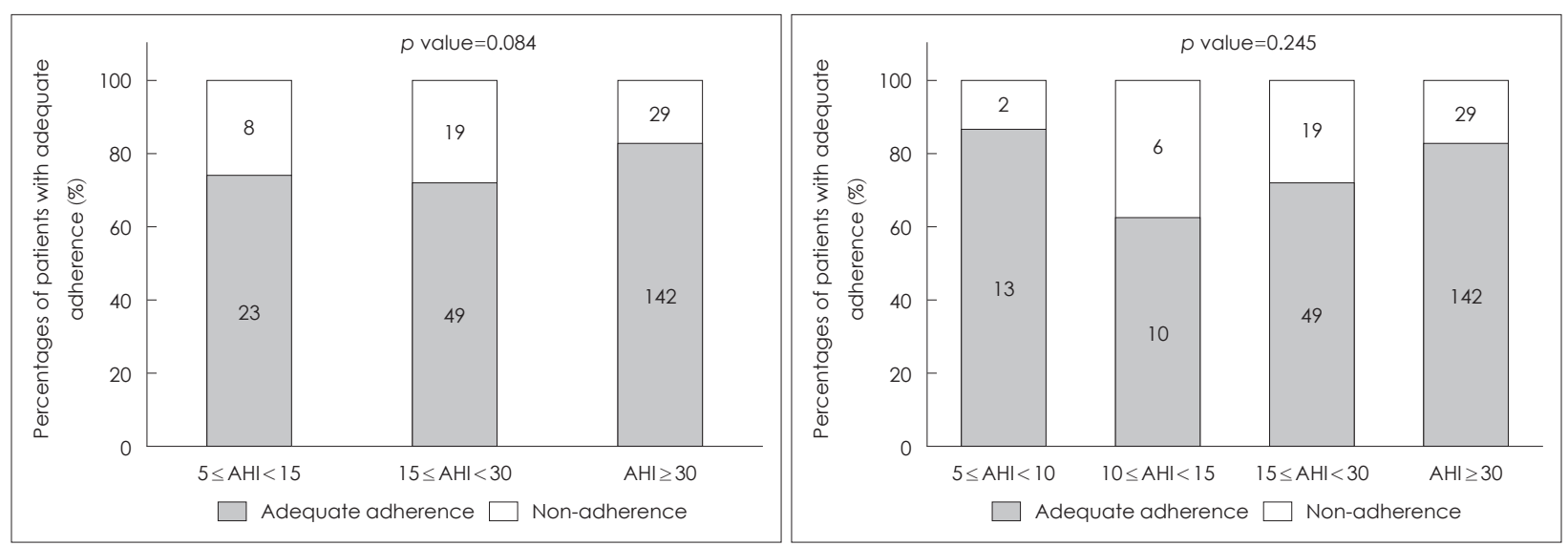

Fig. 2. Percentages of patients with adequate adherence to positive airway pressure therapy in the mild, moderate, and severe obstructive sleep apnea groups. Fisher's exact test. AHI, apnea-hypopnea index. 

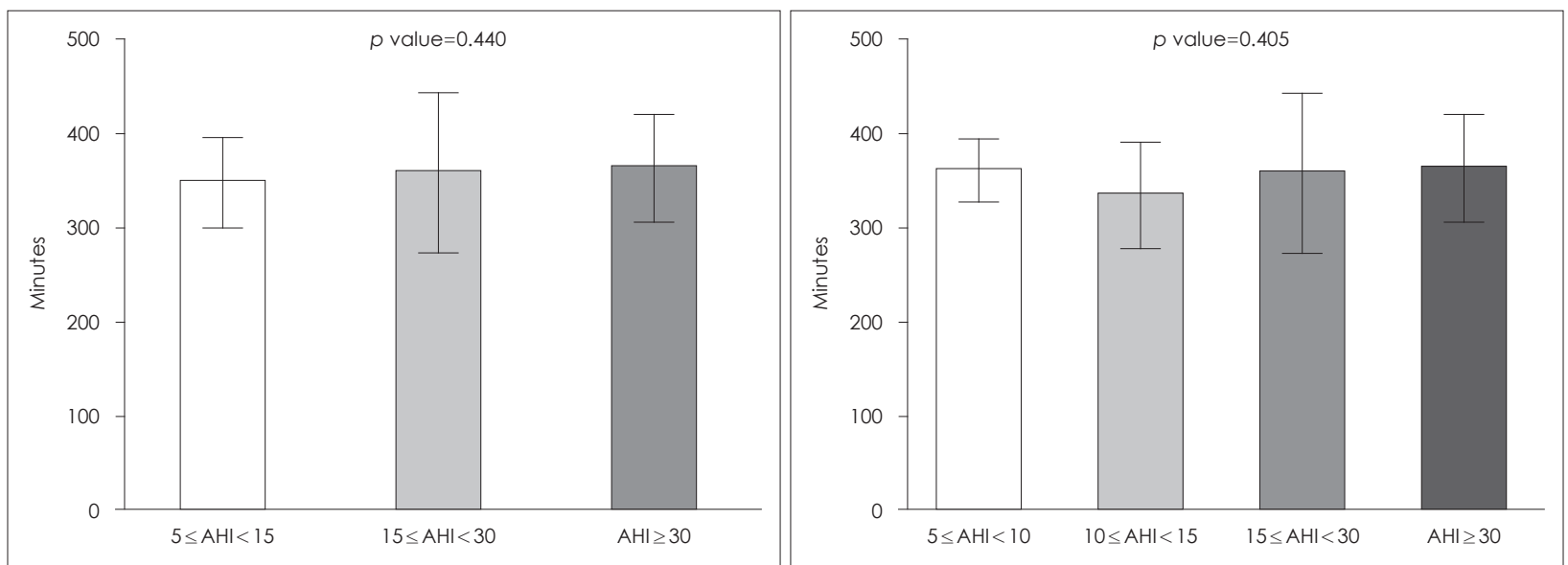

Fig. 3. Mean duration of positive airway pressure device usage during sleep in patients with different obstructive sleep apnea severity. One-way analysis of variance with Bonferroni correction. AHI, apnea-hypopnea index.

reported that $\mathrm{AHI}$ and the percentage of duration with oxygen desaturation of $<90 \%$ were significantly higher in the adequate adherent group than non-adherent group. Moreover, according to a meta-analysis by Madbouly, et al., ${ }^{12)}$ AHI was significantly higher in the adequate adherent group than in the non-adherent group. Therefore, many physicians believe that the severity of OSA might significantly affect adherence to PAP therapy. In addition, Baratta, et al. ${ }^{13)}$ recently performed a cross-sectional study with 295 OSA patients and reported that a low OSA severity was an independent predictor of nonadherence to PAP therapy. However, that study was conducted only in patients with moderate-to-severe OSA (AHI $\geq 15$ ). In addition, our subjects were motivated to use a PAP device for financial benefits from the NHIS during the study period, and there might be some differences in results from other studies. We conclude that the severity of OSA does not affect adherence to PAP therapy in OSA patients. Therefore, physicians should not hesitate to treat mild OSA patients with PAP therapy due to non-adherence to PAP therapy in those patients in South Korea.

To the best of our knowledge, this is the first study that assessed PAP adherence in patients with different OSA severity, including patients with mild OSA, and determined various parameters regarding PAP adherence in mild OSA patients by subdividing them according to their AHI values (5-10 vs. 10-15). In this study, the mild OSA group showed the lowest percentage of days on which subjects used a PAP device for $\geq 4$ h during sleep. Although this observation was not statistically significant, it might indicate that PAP adherence is poor in the mild OSA group. However, in the subgroup analysis in the mild OSA group, the median value of the percentage of days on which a PAP device was used for $\geq 4 \mathrm{~h}$ during sleep was lower in the AHI value 10-15 group than in the other groups; the difference was not statistically significant. Furthermore, we found that the median value of the percentage of days on which a PAP device was used for $\geq 4 \mathrm{~h}$ during sleep was lower in the AHI value 5-10 group (83.90\% vs. 85.70\%) than in the severe OSA group. Therefore, we believe that this tendency was due to the results observed in AHI 10-15 group, and adherence to PAP therapy in the AHI value 5-10 group was not inferior to that in the severe OSA group.

One of the well-known factors related to PAP therapy adherence is patients' socioeconomic status (SES). Bakker, et al. ${ }^{14)}$ performed an observational study with 126 patients and reported high individual socioeconomic deprivation as a significant independent predictor of poor CPAP adherence. In addition, Simon-Tuval, et al. ${ }^{15)}$ reported that patients with low SES are less receptive to CPAP treatment than those with higher SES. Therefore, financial burden of PAP therapy might be considered as an independent factor that negatively affects the continuation of PAP therapy. In this study, the difference in PAP therapy adherence according to OSA severity was not significant because financial benefits were provided equally. As mentioned above, the NHIS in South Korea initially covers $80 \%$ of the PAP device rental fee during the 3-month PAP device adaptation period and continues to provide financial benefits to the patients who use the device for $\geq 4 \mathrm{~h} /$ day and on $70 \%$ of 30 consecutive days; patients need to pay only approximately 15 United States dollars per month for renting the device. A reduction in financial benefits in this situation will result in a decrease in PAP adherence, and it will not be an appropriate measure in terms of reduction in patient morbidity. 
Several studies reported that the percentage of patients with adequate adherence to PAP therapy at 3 months after initiation of PAP therapy was about 50 to $60 \%{ }^{8,16)}$ In addition, the percentage of nights during which the device was used for at least $4 \mathrm{~h}$ at 3 months after initiation of PAP therapy was reported as $49 \pm 36 \%$ or $63 \pm 29 \%$ according to titration proto$\mathrm{col}^{8)}$ In our study, the percentage of patients with adequate adherence to PAP therapy was $79.3 \%$ (216/270), and the percentage of nights during which the device was used for at least $4 \mathrm{~h}$ was $80.13 \pm 20.61 \%$ at 3 months after initiation of PAP therapy. Moreover, a previous study by Kim, et al., ${ }^{17)}$ which was performed in South Korea before the Korean NHIS started to cover PAP therapy, reported that only $34.7 \%$ of patients used PAP device for more than 3 months although their methodology was not exactly the same as that of the present study. We believe that the primary reason for adherence to PAP therapy observed in our study being higher than that observed in previous studies might be due to the alleviation of economic burden by insurance coverage. Therefore, we could confirm once again that reduction in financial burden plays an important role in increasing PAP device adherence.

This study has some limitations. First, it was a retrospective medical record review study; therefore, the authors might not control some confounding factors that affect the results of this study. However, although this study was conducted retrospectively, it included a sufficient number of subjects, and the data was collected intentionally and prospectively. Therefore, we regarded that our result is meaningful as prospective study. Second, the majority of participants were male. Thus, the results of the present study might reflect a selection bias. However, OSA is more prevalent in men than in women because of its nature. Third, the median age of the present study was significantly different among each groups. Therefore, it might also reflect a selection bias and this should be taken account in the interpretation of the results of the present study. Forth, as this study is a retrospective study, it does not include a control group that did not receive financial support. Therefore, our results do not sufficiently reflect this factor. Further research is needed to determine whether our conclusion remains adequate in the long term.

In conclusion, PAP therapy adherence did not differ according to OSA severity in adult patients. Moreover, PAP therapy adherence in the AHI value 5-10 group was not inferior to that in the moderate or severe OSA group. Compared with previous studies, adherence to PAP therapy is very high within the current national insurance system of South Korea. In par- ticular, since there is no difference in PAP adherence according to the severity determined by AHI, aggressive PAP therapy might be considered in patients with mild OSA. This high degree of compliance may have a great influence on the support provided by the national insurance for the prescription of PAP devices. Therefore, it is necessary to continuously expand and maintain the insurance for the health promotion in OSA patient in South Korea.

\section{Acknowledgments}

We would like to thank Editage (www.editage.co.kr) for English language editing.

This study was supported by National Research Foundation of Korea (NRF) grant funded by Korean government (Ministry of Education) (NRF-2020R1I1A1A01063604).

\section{Author Contribution}

Conceptualization: Seung Hoon Lee. Data curation: Seongbin Park, Min Young Seo, Min Kyu Lee, Mun Soo Han, Jun Yoo, Sun Jin Hwang. Funding acquisition: Min Young Seo. Methodology: Seongbin Park, Min Young Seo. Writing — original draft: Seongbin Park, Min Young Seo. Writing — review \& editing: Seongbin Park, Min Young Seo.

\section{ORCIDs}

Seung Hoon Lee

Seongbin Park

https://orcid.org/0000-0001-7811-2692

Min Young Seo

https://orcid.org/0000-0002-1079-6351

Min Kyu Lee

https://orcid.org/0000-0002-1287-6961

Mun Soo Han

https://orcid.org/0000-0001-5124-0651

Jun Yoo

https://orcid.org/0000-0003-1359-6248

Sun Jin Hwang

https://orcid.org/0000-0002-9419-7785

https://orcid.org/0000-0001-9221-0790

\section{REFERENCES}

1) Seo MY, Lee JY, Hahn JY, Ryu G, Hong SD, Dhong HJ, et al. Association of obstructive sleep apnea with subclinical cardiovascular disease predicted by coronary artery calcium score in asymptomatic subjects. Am J Cardiol 2017;120(4):577-81.

2) Epstein LJ, Kristo D, Strollo PJ Jr, Friedman N, Malhotra A, Patil $\mathrm{SP}$, et al. Clinical guideline for the evaluation, management and long-term care of obstructive sleep apnea in adults. J Clin Sleep Med 2009;5(3):263-76.

3) Doherty LS, Kiely JL, Swan V, McNicholas WT. Long-term effects of nasal continuous positive airway pressure therapy on cardiovascular outcomes in sleep apnea syndrome. Chest 2005;127(6):2076-84.

4) Engleman HM, Martin SE, Deary IJ, Douglas NJ. Effect of continuous positive airway pressure treatment on daytime function in sleep apnoea/hypopnoea syndrome. Lancet 1994;343(8897):572-5.

5) Marin JM, Carrizo SJ, Vicente E, Agusti AG. Long-term cardiovascular outcomes in men with obstructive sleep apnoeahypopnoea with or without treatment with continuous positive airway pressure: An observational study. Lancet 2005;365(9464): 1046-53.

6) Seo MY, Lee SH. Compliance with continuous positive airway pressure in patients with obstructive sleep apnea. Sleep Med Res 2020;11(1):7-14.

7) Weaver TE, Grunstein RR. Adherence to continuous positive airway pressure therapy: The challenge to effective treatment. Proc 
Am Thorac Soc 2008;5(2):173-8.

8) Rosen CL, Auckley D, Benca R, Foldvary-Schaefer N, Iber C, Kapur V, et al. A multisite randomized trial of portable sleep studies and positive airway pressure autotitration versus laboratory-based polysomnography for the diagnosis and treatment of obstructive sleep apnea: The HomePAP study. Sleep 2012;35(6):757-67.

9) Iber C, Ancoli-Israel S, Chesson A, Quan SF; American Academy of Sleep Medicine. The AASM manual for the scoring of sleep and associated events. Westchester: American Academy of Sleep Medicine;2007.

10) Riachy M, Najem S, Iskandar M, Choucair J, Ibrahim I, Juvelikian G. Factors predicting CPAP adherence in obstructive sleep apnea syndrome. Sleep Breath 2017;21(2):295-302.

11) Campos-Rodriguez F, Martinez-Alonso M, Sanchez-de-la-Torre M, Barbe F; Spanish Sleep Network. Long-term adherence to continuous positive airway pressure therapy in non-sleepy sleep apnea patients. Sleep Med 2016;17:1-6.

12) Madbouly EM, Nadeem R, Nida M, Molnar J, Aggarwal S, Loomba $R$. The role of severity of obstructive sleep apnea measured by apnea-hypopnea index in predicting compliance with pressure therapy, a meta-analysis. Am J Ther 2014;21(4):260-4.

13) Baratta F, Pastori D, Bucci T, Fabiani M, Fabiani V, Brunori M, et al. Long-term prediction of adherence to continuous positive air pressure therapy for the treatment of moderate/severe obstructive sleep apnea syndrome. Sleep Med 2018;43:66-70.

14) Bakker JP, O'Keeffe KM, Neill AM, Campbell AJ. Ethnic disparities in CPAP adherence in New Zealand: Effects of socioeconomic status, health literacy and self-efficacy. Sleep 2011;34(11):1595-603.

15) Simon-Tuval T, Reuveni H, Greenberg-Dotan S, Oksenberg A, Tal A, Tarasiuk A. Low socioeconomic status is a risk factor for CPAP acceptance among adult OSAS patients requiring treatment. Sleep 2009;32(4):545-52.

16) Kribbs NB, Pack AI, Kline LR, Smith PL, Schwartz AR, Schubert $\mathrm{NM}$, et al. Objective measurement of patterns of nasal CPAP use by patients with obstructive sleep apnea. Am Rev Respir Dis 1993; 147(4):887-95.

17) Kim JH, Kwon MS, Song HM, Lee BJ, Jang YJ, Chung YS. Compliance with positive airway pressure treatment for obstructive sleep apnea. Clin Exp Otorhinolaryngol 2009;2(2):90-6. 